\title{
Cow Care in Hindu Animal Ethics. Kenneth R. Valpey. Palgrave Macmillan, 2020
}

\section{Supratik $\operatorname{Sen}^{1}$ (D)}

Accepted: 8 July 2021 / Published online: 22 July 2021

(c) The Author(s) 2021

Drawing upon a wide range of Hindu textual resources and thinkers, Valpey's work explores our moral obligation to animals, and by extension, the non-human world. Valpey approaches the subject by focusing on a "constructive" approach to the ethics of what he terms "cow care", the practice of keeping and caring for cows throughout their natural lives (Valpey, 2020, p. xvi). He uses the term bovinity to capture the pan-Hindu notion that cows are more than animals and are, in an important sense, privileged beings and therefore worthy of special reverence, care, and protection. Valpey writes that his treatise primarily functions as "an extended commentary" to the Bhagavad Gītā's (5.18) characterization of a wise or well-educated person as one who sees all living beings with "equal vision", and through his multi-faceted scriptural exegesis, he endeavours to highlight the implications of this worldview for animal ethics (Valpey, 2020, p. 3). Admittedly, Valpey's book is a "wide-ranging overview" (Valpey, 2020, p. 5) of a sprawling topic; nonetheless, it makes a significant contribution to the burgeoning discipline of Hindu animal ethics (and Hindu ethics) for four reasons.

First, it captures the constellation of meanings associated with the term "cow" in the Hindu cosmos through a diachronic textual survey of the voices of Brahmanical Hinduism. This survey allows Valpey to argue that Hindu texts, from their earliest redaction, consistently advocate a vision of cosmic order that turned on the idea of a symbiotic relationship between natural, human, and divine; inter-relationships which humans ought to nourish through ritual and devotion to a supreme divinity. Perhaps, the most significant from the perspective of ethics is Valpey's nuanced articulation of how cosmic order, and correspondingly, human well-being, is sustained by acknowledging the "explicit link between cows, the care of cows, and human right action, dharma" (Valpey, 2020, p. 24).

Valpey elaborates on this theme in the third chapter by focusing on how "cows in modern India are situated in 'contested fields' of differing convictions about their proper place in ethical discourse and practice" (Valpey, 2020, p. 95). In exploring

Supratik Sen

supra82sen@gmail.com

1 Faculty of Theology and Religion, University of Oxford, Oxford OX1 2JD, UK 
and clarifying modern Indian sensibilities toward cows and cow care, Valpey revisits ancient texts like the Manusmriti and the Mahabharata to argue that these texts prefer the way of ahimsa (non-violence), inasmuch as they prefer the path of nivrtti, the path of ascetic morality aimed at promoting its practitioner to a state permanently untouched by the cycle of rebirth and its attendant death and decay. However, Valpey is not content with highlighting the ethical implications of the practice of nonviolence. For Valpey, the principle of dharma manifesting in the endeavour to avoid harming cows (animals) is not sufficient to help humans transcend the "realm of selfish interest", "the stuff of anthropocentrism", and the ahamkara-based vision that perpetuates our alienation from nature and undermines our efforts to sustain the principle of caring for cows as "beings in their own right, rather than objects of ownership" (Valpey, 2020, p. 159-160). Rather, Valpey contends that the bhakti dimension of Hindu religious thought and practice is the "complementary counterpart to dharma in the Hindu calculus of cultural meaning" and that it is bhakti theology and practice that can actualize authentic transformation in being, the kind of transformation that will allow us to embrace and live in the consciousness of being humble servants of all divinely originated sentient beings (Valpey, 2020, p. 101). Valpey makes the case for the superlative potency of bhakti in effecting self-transformation and consequent ethical transformation in a number of ways throughout the book, and in this sense, Cow Care can be read as an argument, through animal ethics, of seeing bhakti as both the natural and necessary culmination of the two other principal paradigms of Hindu thought-dharma and yoga. This construal of bhakti as the indispensable ingredient needed to complete any process of ethical transformation is the second reason why Valpey's work is important to the emerging discourse on animal ethics and ethics in general.

The third reason which makes Valpey's work notable is that he engages with the abolitionist perspective which claims that the practice of cow care, in all its shapes and forms, is intrinsically exploitative and is akin to human slavery. While being sympathetic to the idea that animal care practices must be constantly reassessed to eliminate abuse, Valpey reiterates the idea that human-bovine interactions, done conscientiously, is a prime example of "how human-nonhuman animal symbiosis functions in the greater context of a world order of interdependence" (Valpey, 2020, p. 205). Valpey extends his argument by incorporating Sue Donaldson's and Will Kymlicka's proposal to extend the concept of citizenship to be inclusive of domestic animals. Valpey elaborates that the paradigms of dharma, yoga and bhakti are capable of offering a "comprehensive basis for recognizing certain nonhuman animals as citizens-in at least an analogical sense-within communities that are committed to these values" (Valpey, 2020, p. 205).

The book's fourth, and I believe, the most significant contribution to animal ethics, is that it makes a preliminary attempt to assess the veracity of the psychobehavioural thesis of non-anthropocentrism, the claim that people who believe that non-human beings have intrinsic value are more likely to behave in ethically sensitive ways toward them. The psycho-behavioural thesis of non-anthropocentrism rests on a problematic assumption: that if people believe that non-human beings are subjects in their own right and are thus intrinsically valuable, then they really will act in more ethically sensitive ways toward them. However, this assumption cannot 
be justified by purely a priori philosophical reasoning since it is an empirical claim about social and cultural reality, and to be credible, it must be open to empirical testing. Despite the fact that the psycho-behavioural thesis of non-anthropocentrism has attained almost canonical status within environmental ethics and animal ethics, very few sociological studies have been done on the psycho-behavioural thesis of non-anthropocentrism and its effects. Admittedly, Valpey's work is technically not a sociological study that explores the empirical implications of non-anthropocentrism, yet Valpey does take a much-needed empirical turn in chapters four and six, when he explores the practical impact of projects and communities, committed, in principle at least, to the psycho-behavioural thesis of non-anthropocentrism. In doing so, Valpey has paved the way for future interdisciplinary work that combines the resources offered by philosophical theology and the social sciences to make a robust case for the extent to which belief systems and worldviews actually drive attitudes and behaviours.

Open Access This article is licensed under a Creative Commons Attribution 4.0 International License, which permits use, sharing, adaptation, distribution and reproduction in any medium or format, as long as you give appropriate credit to the original author(s) and the source, provide a link to the Creative Commons licence, and indicate if changes were made. The images or other third party material in this article are included in the article's Creative Commons licence, unless indicated otherwise in a credit line to the material. If material is not included in the article's Creative Commons licence and your intended use is not permitted by statutory regulation or exceeds the permitted use, you will need to obtain permission directly from the copyright holder. To view a copy of this licence, visit http://creativecommons.org/licen ses/by/4.0/.

\section{Reference}

Valpey, K. R. (2020). Cow care in Hindu animal ethics. Palgrave Macmillan. https://doi.org/10.1007/ 978-3-030-28408-4

Publisher's Note Springer Nature remains neutral with regard to jurisdictional claims in published maps and institutional affiliations. 